\title{
Cash Flow Management for Financial Decision Making in SMB's in Villavicencio City
}

\author{
Agustín María Martínez Vargas \\ Corporación Universitaria Minuto de Dios
}

\begin{abstract}
Day-to-day information on the behavior of cash in economic entities, which at the same time reflects in cash flow and its management, marks the difference. This will allow the entrepreneur to make correct financial decisions, minimizing risk and possible bankruptcy. The present research objective is to explain the management of cash flow made by managers and owners of SMB's, based on financial decision making. To do so, a mixed investigation is carried out. Based on a survey applied to 278 SMB's managers in Colombia, a descriptive and explanatory analysis based on binary logistic regression is performed to predict twelve (12) criterion variables. In addition, information is managed through records oriented to the management of multipurpose events, where training, informal discussion as a focus group and observation of the participants' reactions to the intention and significance of the project are the essence. The results show that the management of cash flow and short-term financial decisions are determined by the educational level of the directors of the SMB's, as well as the type of company and the number of employees, with the manifest need for financial training to the respect.

making evident the need for financial training to the respect.
\end{abstract}

Keywords: Financial management; liquidity; solvency; working capital; binary logistic regression. 